Article

\title{
Coupling Coordination of the Regional Economy, Tourism Industry, and the Ecological Environment: Evidence from Western China
}

\author{
Fengting Zhang ${ }^{1, *(\mathbb{D}}$, Md Nazirul Islam Sarker ${ }^{2, * \mathbb{D}}$ and Yang Lv $^{3} \mathbb{( D}$ \\ 1 Institute of Cultural Tourism, Sichuan Vocational College of Cultural Industries, Chengdu 610213, China \\ 2 School of Political Science and Public Administration, Neijiang Normal University, Neijiang 641112, China \\ 3 College of Teachers, Chengdu University, Chengdu 610106, China; lvyang@cdu.edu.cn \\ * Correspondence: zftsis369@163.com (F.Z.); sarker@njtc.edu.cn (M.N.I.S.)
}

check for updates

Citation: Zhang, F.; Sarker, M.N.I.; Lv, Y. Coupling Coordination of the Regional Economy, Tourism Industry, and the Ecological Environment: Evidence from Western China. Sustainability 2022, 14, 1654. https://doi.org/10.3390/su14031654

Academic Editor: Fabio Carlucci

Received: 22 December 2021

Accepted: 26 January 2022

Published: 31 January 2022

Publisher's Note: MDPI stays neutral with regard to jurisdictional claims in published maps and institutional affiliations.

Copyright: (c) 2022 by the authors. Licensee MDPI, Basel, Switzerland. This article is an open access article distributed under the terms and conditions of the Creative Commons Attribution (CC BY) license (https:/ / creativecommons.org/licenses/by/ $4.0 /)$.

\begin{abstract}
The economic-tourism-environment (ETE) is a complex system with extensive connotations and coupling characteristics. The exact understanding of these systems forms the prerequisite and basis for regional development. This study explores the impact of the coupling coordination of the ETE system on the level and influencing factors of sustainable development in western China. An evaluation index system has been developed for assessing the coupling coordination (CC) of the ETE system based on the context of 12 provinces and cities in western China. Entropy and spatial autocorrelation methods have been used to evaluate the comprehensive benefit value and influencing factors of the ETE systems in the region. The spatial Durbin model has been used to assess empirical data from 2010-2019. The coupling coordination degree (CCD) of each subsystem was used as the main explanatory variable to quantify the spatial spillover effect. The research results show that the ETE system of the provinces and cities in western China have a strong correlation. The three subsystems interact, restrict, and promote each other, operating together in contradictory unity. The degree of coupling and coordination of the ETE systems are mainly stable but fluctuate from the time perspective. From the spatial perspective, the level of coupling and coordination have clear spatial correlation and spatial dependence. However, since 2013, the spatial dependence has significantly weakened, indicating that the level of coupling coordination is moving towards a balanced direction. The ETE subsystems not only promote the improvement of the coupling coordination of the region itself, but also optimize the coupling coordination of neighboring areas. The promotion effect of each subsystem on the degree of self-coupling and coordination is greater than the promotion effect on neighboring areas.
\end{abstract}

Keywords: regional economy; tourism industry; ecological environment; coupled and coordinated development; systems interaction

\section{Introduction}

The degree of coordination of a coupling system is critical for regional growth and economic development. With the regular implementation of integrated environment and tourism development policies, eco-tourism development, eco-economic policies, and other strategic policies, the pattern of integrated economic, tourism, and environmental development are highlighted at the community and national levels [1]. While growth of an area's economy and tourism will generate enormous economic and social advantages, it may also wreak havoc on the natural environment and increase transportation costs [2]. When environmental degradation exceeds a certain point, it raises the cost of economic activity and limits the long-term development of the area's tourism [3]. Meanwhile, unbalanced economic, environmental, and transportation development has resulted in a variety of problems, including the resource scarcity phenomenon, an imbalance between tourism and economic development, and possible environmental hazards associated with tourism and 
economic growth [4-6]. Academics have demonstrated a strong interest in investigating the relationship between the tourism, economics, and environment subsystems, with most research focusing on cross-sectional data or a brief period of time [7-10]. However, comprehensive study remains scarce on the coupling coordination degree (CCD) and analysis of the economic-tourism-environment (ETE) subsystems and on the identification of their influencing factors. Thus, quantitative analysis of the ETE coupling coordination relationship is critical for achieving sustainable regional development [3,11-13]. Therefore, this study intends to explore the impact of the coupling coordination of the ETE system and its influencing factors of sustainable development in western China.

Due to higher interconnectedness, relevance, and potential, modern tourism is playing an increasingly essential economic role in regional development [1] for which it is frequently one of the most effective strategies [8]. The Chinese government has repeatedly emphasized maintaining its strategic determination to strengthen and promote the construction of ecological civilization [14], thus creating ecological safety. Tourism, as one of the ways to promote Chinese regional economic development, was once known as the smoke-free industry and achieved rapid growth. With a background of "green water and green mountains are golden mountains and silver mountains" and ecological environment (EE) protection, the tourism industry's development can vigorously solve the ecological environment's constraints on social and economic development in the new era [12]. As a vital pillar industry in China, the tourism industry is also inseparable from strong support for the economic foundation and the basic guarantee of the environment [15]. However, with the tourism industry's rapid development, its adverse impact on the environment has gradually emerged. The extent and depth of the impact have also increased, thus endangering the safety of the ecosystem of tourist destinations [16]. Therefore, coordinating the conflict between the economy, the tourism industry, and ecological environmental protection, maintaining the ecological safety of tourist destinations, and improving the quality of regional economic development are becoming hot issues that have attracted much attention $[5,11,17,18]$. Studying the coupling coordination relationship between ETE systems has practical implications for promoting sustainable economic development, improving the EE, and supporting the sustainable development of tourism destinations.

The coupling coordination relationship is a term that means the interaction and mutual impact of two or more systems that are connected in some way [3,19-21]. The connection between systems will grow through time, culminating in a transition from discord to coordination. The three systems (ETE) stated above have a major influence on regional economic development: they interact and are highly correlated. Most existing research focuses on the pairwise interactions between tourism [4,22], urbanization [9,23], and the EE $[18,24]$. Only a few studies incorporate the ETE systems into a single research framework, and even fewer investigate their coupling relationships [4,24]. Additionally, most research is conducted on a provincial or smaller regional scale rather than on a national scale. Tourism, urbanization, and the natural environment are inextricably linked, and the concept of internal development is consistent [25]. Tourism contributes to urban economic development and increases urbanization levels, whereas urban development creates the infrastructure and public space necessary for tourism [26]. A healthy EE is necessary for the tourism industry and urbanization to grow sustainably [27]. Thus, research into the interaction between tourism, urbanization, and the EE is practical for encouraging high-quality regional tourism development, adopting novel urbanization strategies, and enhancing the EE. Due to the disparities in resource conditions and economic development levels between tourism cities in eastern, central, and western China, the level of urbanization development is unbalanced, impeding the sustainable growth of new urbanization in China. Investigating the relationship between the development mode and evolution characteristics of the ETE system in China enables the tourism cities to tailor their tourism development mode to their actual circumstances. This can aid in the promotion of urbanization and the implementation of China's ecological civilization. 
Research on eco-tourism security began in the 20th century, emphasizing the "systems integration" perspective of the tourism industry to enhance the organic integration of social and economic ecological systems [14]. In recent years, scholars have assessed the connection between tourism and regional economic and $\mathrm{EE}$ with numerous research findings $[1,3,5]$. Western scholars mainly discuss the cooperation mechanism between the tourism industry and the environmental system [22,28]. Due to the paradox between tourism and the $\mathrm{EE}$, the focus is mainly on the impact of tourism on the EE [29]; the sensitivity of the tourism EE [30]; the carrying capacity of the tourism EE [31]; factors affecting tourists' environmental awareness [32]; environmental regulations; and carbon emissions; etc., [33]. Chinese scholars analyze the tourism ecological security system from multiple dimensions (e.g., that of the social economy or the EE) and the relationship between various dimensions within the system. This can be divided into three systems of coupling and coordination research [1,27]: interactive response research [1,34], exploring the relationship of interactive coercion [5,23,35]; research on spatial displacement [36]; and research on the temporal and spatial differentiation of efficiency, etc. Through exploring the existing research, the research perspectives are found to include the characteristics of tourism, economics, ecology, and geography. The research content has expanded from the earliest economic and environmental system to tourism economics [22] and the EE [12,37]. The analysis of the CCD of each system has been extended to prefecture-level cities, provinces, and economic belts across China. The research methods continue to innovate based on the coupling degree model. However, most existing studies use single research methods and tools, and few combine multidisciplinary methods and tools, such as the use of mathematical models $[6,9,16]$ and spatial exploratory analysis for investigation $[9,12]$. It is especially rare to use spatial econometric analysis to measure the CCD level of the economy, tourism, and the environment and to combine research and exploration with influencing factors from a spatial perspective.

The western region of China is rich in natural resources; its climate, landforms, vegetation, etc., are unique, and it has unique tourism resources. It is also an "important area of the Silk Road Economic Belt." Taking the Silk Road Economic Belt initiative as an opportunity for tourism in the west, the industry has achieved rapid development. However, the western region's ecological environment is comparatively fragile, while the rate of economic development is relatively slow. Tourism industry development is a significant basis for the economic growth of the western region. In view of this, the current study uses western China as the study area. The problematic factors of the regional economy-tourism industry-ecological system coupled with the level of coordination are shown. In addition, the spatial Durbin model analyzes the spatial spillover effect of the CCD of each subsystem on the degree of ETE coupling coordination. With an aim of informing the economy and formulating the direction for China's western region, this study mainly focuses on three specific issues. Firstly, it explores the connotation and interaction mechanism of the coupling and coordination between the ETE systems; secondly, it selects and construct a multi-index evaluation system for the ETE system, using the comprehensive evaluation model and the CCD model to quantity the characteristics of time and space coupling and coordination; and, thirdly, it offers a theoretical base and decision-making reference for realizing the coordinated and sustainable development of the ETE system.

\section{Literature Review}

\subsection{Connotations of Coupling and Coupling Coordinated Development}

The term "coupling" is widely used in biology, ecology, agriculture, geography, and other fields [9]. The term first emerged in physics and referred to the electrical circuit elements influenced by interacting with networks, the cooperative transmission of energy, and the information division process. The study of system relationships describes the phenomenon of mutual influence, interaction, and even unity between systems or elements [7]. They form a dynamic relationship of mutual coercion, mutual dependence, and mutual influence between subsystems or elements within the system [38]. This portrays a 
particular system's revolutionary situation or trend at a certain point in time $[14,35]$. When the systems or its internal elements are properly coordinated and mutually beneficial, it is a benign coupling. Conversely, when they rub against each other and hinder each other, it is a vicious coupling. The coupling degree is usually applied to explain the interaction level between systems or elements, regardless of their pros and cons. Coordination is a benevolent interrelationship among systems or system elements; it describes a relationship between subsystems which is coordinated, harmonious, and worthy. Coordination is the vigorous growth of multiple systems or elements. The guarantee coordination system is a tool of assessment of the sustainable development of system elements or of each element's sustainable development [39]. The harmony process focuses on the size of the benign interaction between the degree of coupling [9]. Development refers to the change process of the system or of its constituent elements from small to large, from simple to complex, from low to high, from disorder to order: the converse is called "negative development" or "reverse development." If development lies between these two and maintains the status quo, it is called zero development [40]. As development is the evolutionary process of a system itself or of a system's elements, it may even be based on the destruction of other systems or elements as its development conditions.

Therefore, the coordinated development of coupling should be the combination of "coupling," "coordination," and "development." It is the system or system elements that go from simple to complex based on proper coordination, harmony, and consistency, and a virtuous circle. The overall evolutionary process is from order to disorder, from lowlevel coordination and optimization to high-level coordination and symbiosis [9]. At the same time, it is also an integrated, comprehensive, diversified, endogenous, and gainful development of aggregation behavior. The coupling and coordinated development pursues a vision of advancing side by side, with overall improvement, overall optimization, and common development [9]. Based on the previous studies, this study defines the relationship between the three major systems of ETE as the "coupling coordination degree of the ETE system" [24]. An index system and model of the CCD have been constructed to measure the relationship and degree of coordination between these three systems. This reflects the synchronization of the development speed and direction of the three subsystems, such as their social and economic benefits, tourism industry development level, and ecological environmental benefits. It also reflects the level of comprehensive development of the ETE subsystems [39] and construction of the index system and CCD model to quantitatively measure the ETE relationship and degree of coordination.

\subsection{Coupling and Coordinated Development Mechanism}

Research on the relationships and mechanisms of the economy, tourism, and ecology is not new. Wall and Wright [41] elaborated on the influence of tourism on the ecology and analyzed the interaction mechanism between the two. Smith [42] argued that there are positive and negative effects of tourism on the ecology. Gössling [43] conducted an in-depth discussion on environmental issues that could be brought about by tourism activities, such as land cover, energy use, biological exchange, and the extinction of wild species. Day and Cai [44] and others specifically studied the problems of energy and the environment on regional tourism's sustainable development in the United States (US) and China.

The ETE is a complex system with extensive content and dynamic coupling relationships. It is also an open system with economic labor and production as the link, tourism development and construction as the space carrier, and a natural ecological system. It is a composite interactive system with distinct characteristics coupled by a common interface. An in-depth knowledge of the relationship and interaction mechanism amid these three systems addresses the major problems of the CCD of the ETE (as shown in Figure 1). 


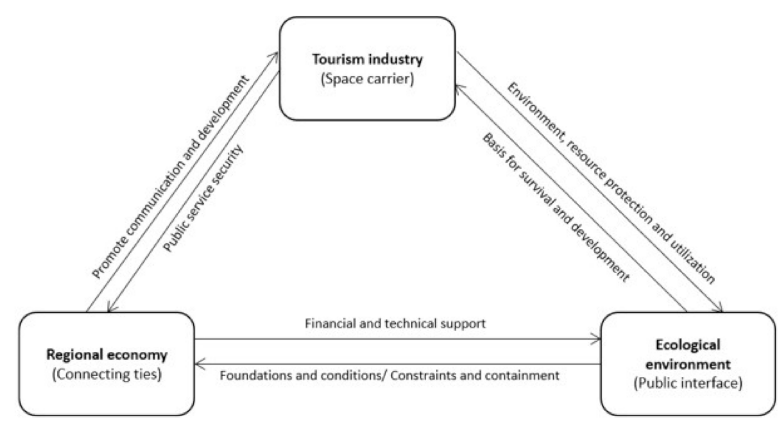

Figure 1. Mechanism of coupling coordinated development of the ETE system.

The ETE subsystems influence, restrict, and promote each other, and operate together in a contradictory unit. The relationships and complexities can be explained as follows. Firstly, the regional economy can generate positive externalities (environmental protection and ecological development of tourism) and negative externalities [45]. The positive externalities are manifested in the growth of regional economic benefits that not only provide a strong financial guarantee and technical support for ecological environmental protection, but also change the mode of resource utilization from a high-pollution extensive type to a low-pollution intensive type. The rapid development of the regional economy can provide basic public services for the development of tourism, such as a capital guarantee, perfect infrastructure, and tourism service-supporting facilities, and enhance the accessibility and attractiveness of tourist attractions, etc., [36]. The higher the rate of economic growth, the higher the income that residents have at their disposal, and the greater the possibility of participation in tourism activities.

Secondly, the tourism industry becomes a space carrier for coordinating the development of the economy and the environment owing to its strength as an economic driving force and its encouragement of low pollution. While tourism promotes the development of regional catering, accommodation, entertainment, transportation, telecommunications, etc., it also promotes the flow of resources, information, and people, thereby increasing the degree of openness of the regional economy. Through the development of eco-tourism, science tourism, and education tourism, etc., it can perform a main role in protecting the natural environment and the rational use of resources.

Finally, a decent EE may be a basis of and condition for social and economic activities. Human beings obtain natural resources from the environment for economic development. The better the natural conditions, the more resources that mankind can obtain, and the better the conditions for economic development [46]. Ecological tourism is also based on the EE; the environment is an economically valuable resource for sustainable development, in which tourism is a prerequisite for survival and continued development [31]. However, with the economy and tourism developing, they inevitably impact upon the EE. This impact constitutes damage to the EE when it reaches a certain level. The destruction of the EE restricts the economy and tourism in many aspects [4]. Such development in China has hindered its consequent development due to these obstacles [47]. Tourism's ecological damage to the environment makes some scenic areas unattractive to tourists, eventually leading to the decline of tourism in the region. The destruction of the EE also increases the expense of economic activities [45]. Governing and improving the EE consume part of the funds, thus leading to the slowing of economic development.

\section{Materials and Methods}

\subsection{Features of the Study Area}

The selected study area includes 12 provinces, cities, and autonomous regions of western China, comprising five provinces in the southwest (Chongqing, Sichuan, Yunnan, Guizhou, Tibet), five provinces in the northwest (Shaanxi, Gansu, Qinghai, Xinjiang, Ningxia), Inner Mongolia, and Guangxi. The total area is about $686 \mathrm{~km}^{2}$, covering $72 \%$ of China and 3.795587 billion people (29\% of China's total population). In 2020 , the total 
gross domestic product (GDP) of the study area was 213,292 billion yuan, accounting for $21 \%$ of China's GDP. Most of the western region is economically backward and needs to be developed except Chongqing, the Sichuan basin, and the Guangzhou plainland. The western region comprises a vast territory, but the population density is comparatively sparse. This is due to the relatively poor topographic and climatic conditions in this region. The plainland area accounts for $42 \%$ of the land resources, while the basin area is less than $10 \%$, with about $48 \%$ of the total population. The land resources are deserts (including the Gobi Desert), Rocky Mountains, and alpine regions $3000 \mathrm{~m}$ above sea level. The vastness of the western region is the reason why the geographical conditions are complex and diverse, with obvious climate differences. The species of animals and plants are ever-changing. The ethnic culture and folk customs are gorgeous and charming, forming a natural and humanistic tourism resource of great development value. However, serious environmental hazards lie behind the rapid development of the regional economy and tourism industry. In addition, the economic scale and industrial structure of various provinces and cities are quite different. The degree of impact on and protection of the ecological environment (EE) is also different. The phenomenon of resentment towards the economic-tourism-environment (ETE) system in China has become more frequent, and the degree of vulnerability between the various elements of the system has become more prominent. Therefore, using scientific methods to quantitatively analyze the ETE coupling and coordination level between provinces and cities in western China has great implications for the realization of regional sustainable development.

\subsection{Data Sources}

The data for this study were mainly collected from the 2010-2019 China Tourism Statistical Yearbook, China Regional Economic Statistics Yearbook, China Environmental Statistics Yearbook, and the statistical yearbooks of the 12 provinces and cities in the western region. Some data were from sections on the 12 provinces and cities in the 2010-2019 China Urban Statistical Yearbook and the National Economic and Social Development Statistical Bulletin. Some missing data were supplemented by linear interpolation.

\subsection{Development of Evaluation Index}

Establishing a rational evaluation index system is the basis for and key to research on the degree of coupling and coordination of the ETE system in the western region of China. To present the CCD role of the tourism industry in the regional economy and the $\mathrm{EE}$, the three major subsystems of the ETE were placed at the same level for research. The selection of evaluation indicators followed the principles of completeness, independence, systematization, operability, dynamics, and relative stability, drawing on existing related studies $[4,7,24,39,48]$. A CCD evaluation index system comprising 26 evaluation indicators has been constructed focusing on the three subsystems of the ETE and combining the social and economic growth of western China, the characteristics of the tourism, and the status quo of the EE (Table 1).

Table 1. Evaluation index system and weight of coordination degree of ETE coupling.

\begin{tabular}{|c|c|c|c|}
\hline Subsystem & Evaluation Index & Weights & References \\
\hline \multirow{8}{*}{ Regional economy } & GDP per capita (10,000 yuan/person) & 0.1774 & {$[6,18,35,49]$} \\
\hline & $\begin{array}{l}\text { Per capita local public budget revenue }(10,000 \\
\text { yuan/person) }\end{array}$ & 0.1453 & {$[3,18,39,50,51]$} \\
\hline & $\begin{array}{l}\text { Added value of secondary industry accounts for } \\
\text { the proportion of GDP }(\%)\end{array}$ & 0.1382 & {$[1,37,40,52]$} \\
\hline & $\begin{array}{l}\text { Added value of tertiary industry accounts for the } \\
\text { proportion of GDP }(\%)\end{array}$ & 0.0953 & {$[1,37,40,49,53]$} \\
\hline & Urban registered unemployment rate $(\%)$ & 0.1125 & {$[18,39,54-56]$} \\
\hline & Proportion of urban population (\%) & 0.0559 & {$[9,17,37,57,58]$} \\
\hline & Public transport vehicles per 10,000 people (units) & 0.1497 & {$[2,9,17,37]$} \\
\hline & Per capita road area $\left(\mathrm{m}^{2}\right)$ & 0.1257 & {$[3,17,35,37,59]$} \\
\hline
\end{tabular}


Table 1. Cont.

\begin{tabular}{|c|c|c|c|}
\hline Subsystem & Evaluation Index & Weights & References \\
\hline \multirow{10}{*}{ Tourism Industry } & Revenue from domestic tourism (100 million yuan) & 0.1897 & {$[9,17,37,53]$} \\
\hline & Inbound tourism income (US $\$ 10,000$ ) & 0.0731 & {$[6,18,35,40]$} \\
\hline & Domestic tourists number (10,000 people) & 0.1154 & {$[18,39,54,60]$} \\
\hline & Inbound tourists number $(10,000$ people $)$ & 0.0735 & {$[9,17,37]$} \\
\hline & Star-rated hotels number (pieces $/ \mathrm{km}^{2}$ ) & 0.1060 & {$[6,18,35]$} \\
\hline & Number of travel agencies (units $/ \mathrm{km}^{2}$ ) & 0.0778 & {$[3,18,39]$} \\
\hline & $\begin{array}{l}\text { Per capita consumption level of tourism } \\
\text { (yuan/person) }\end{array}$ & 0.0794 & {$[1,37,40]$} \\
\hline & Proportion of tourism income in GDP (\%) & 0.1281 & {$[3,10,37]$} \\
\hline & $\begin{array}{l}\text { Proportion of tourism employees in tertiary } \\
\text { industry }(\%)\end{array}$ & 0.1078 & {$[3,10,37,53]$} \\
\hline & Inbound tourism stays time (days [d]) & 0.0492 & {$[3,10,37]$} \\
\hline \multirow{8}{*}{ Ecological environment } & Park green area per capita $\left(\mathrm{m}^{2}\right)$ & 0.1548 & {$[10,18,37]$} \\
\hline & Green built-up area rate $(\%)$ & 0.1329 & {$[10,18,37]$} \\
\hline & Ambient air quality index $(\%)$ & 0.1367 & {$[38,53,61,62]$} \\
\hline & Urban sewage treatment rate $(\%)$ & 0.1197 & {$[5,6,49,63]$} \\
\hline & $\begin{array}{l}\text { Rate of treatment for pollution-free domestic } \\
\text { garbage }(\%)\end{array}$ & 0.1159 & {$[9,18,24,64]$} \\
\hline & $\begin{array}{l}\text { Annual emissions of industrial waste water } \\
\text { (10 } 4 \mathrm{t} / \text { million) }\end{array}$ & 0.1288 & {$[9,18,24,64]$} \\
\hline & $\begin{array}{l}\text { Industrial sulfur dioxide emissions } \\
\text { (10 } 4 \mathrm{t} / \mathrm{million})\end{array}$ & 0.1137 & {$[9,18,24,64]$} \\
\hline & $\begin{array}{l}\text { In general, industrial solid waste emissions } \\
(104 \mathrm{t} / \text { million })\end{array}$ & 0.0975 & {$[17,24,37]$} \\
\hline
\end{tabular}

\subsection{Research Methods}

\subsubsection{Entropy Method and Subsystems Evaluation}

The improved entropy method determines the index's weight by calculating the index's information entropy $[5,28]$. Compared with other weighting methods, it is more objective and overcomes the shortcomings of subjective weighting [40]. The calculation steps are as follows:

Step 1: Construct the index matrix, supposing that the original index data matrix $x=(x i j)(i=1,2 \ldots n, j=1,2 \ldots m)$ is formed by $n$ evaluation objects and $m$ evaluation indexes. In this study, $n$ represents 12 provinces in western China, and $m$ represents 26 secondary indicators. The index matrix is as follows:

$$
X=\left[\begin{array}{rrrl}
x_{11} & x_{12} & \ldots & x_{1 m} \\
x_{21} & x_{22} & \ldots & x_{2 m} \\
\vdots & \vdots & \ddots & \vdots \\
x_{n 1} & x_{n 2} & \ldots & x_{n m}
\end{array}\right]
$$

Step 2: Processing of data standardization; due to the different dimensions of the selected indicators, the data cannot be directly compared; thus, data standardization processing is required. The indicator attributes can be separated into two categories: positive and negative indicators. Positive indicators have a positive change on the system, while negative indicators have a negative effect. The equations for calculating positive and negative indicators are as follows:

$$
\begin{aligned}
& \text { For the positive index, } X \prime i j=\frac{x_{i j}-\min \left(x_{i j}\right)}{\max \left(x_{i j}\right)-\min \left(x_{i j}\right)} \\
& \text { For the negative index, } X^{\prime} i j=\frac{\max \left(x_{i j}\right)-\min \left(x_{i j}\right)}{\max \left(x_{i j}\right)-\min \left(x_{i j}\right)}
\end{aligned}
$$


Step 3: Calculate the proportion of indicators,

$$
P i j=\frac{X_{i j}^{\prime}}{\sum_{i=1}^{n} X_{i j}^{\prime}}
$$

Step 4: Information entropy of the indicator,

$$
E j=\sum_{i=1}^{n} P_{i j} \ln \left(P_{i j}\right)
$$

Step 5: Redundancy of information entropy,

$$
D j=1-E j
$$

Step 6: Weight of the indicator,

$$
W j=\frac{D_{j}^{\prime}}{\sum_{j=1}^{m} D_{j}^{\prime}}
$$

where, $n$ denotes index number and $m$ denotes time (year). Pij represents proportion of indicators; $E j$ denotes information entropy; $D j$ represents redundancy, and $W j$ denotes weight of the indicator.

The contribution of the three subsystems of ETE is equally important. The indicators under each subsystem are also equally important. All indicators' weights are assigned using the domain averaging approach, which means that each subsystem is given the same weight, and all indicators in the same field are given the same weight $[18,26]$. In this method, the weight is objectively set $[55,63]$. Furthermore, the procedure is relatively simple. The weight calculation results are presented in Table 1.

\subsubsection{Calculation of the Comprehensive Evaluation Index}

The linear weighting technique is applied to estimate the coordinated development of the ETE in western China from 2010-2019. The comprehensive benefit evaluation functions of these three subsystems are as follows:

$$
\begin{gathered}
f(x)=\sum_{j=1}^{m} W_{j} P_{i j}(i \text { is the number of provincial administrative regions, } j \text { corresponds to eight indicators of the regional economic subsystem }) \\
g(y)=\sum_{j=1}^{m} W_{j} P_{i j}(i \text { is the number of provincial administrative regions, } j \text { corresponds to } 10 \text { indicators of the tourism industry subsystem }) \\
h(z)=\sum_{j=1}^{m} W_{j} P_{i j}(i \text { is the number of provincial administrative regions, } j \text { corresponds to eight indicators of the EE subsystem }) \\
\qquad T=\sum_{j=1}^{m} W_{j} P_{i j}
\end{gathered}
$$

where $i$ is the provincial-level administrative regions number and $j$ is the benefit value of comprehensive evaluation, corresponding to the coordinated development level of ETE, a total of 26 indicators.

In these equations, $f(x), g(y)$, and $h(z)$ represent the comprehensive benefit value of the three subsystems of the ETE, respectively. Specifically, $i$ is the number of provincial administrative districts; $j$ is the index in each system; $W j$ is the weight of each indicator in the three systems; P $i j$ is the dimensionless standardized worth of every indicator in area $i$ in each system; and $T$ denotes the coupling and coordination of the ETE system in western China. The comprehensive evaluation benefit value of development of the ETE is considered equally important in this study. Hence, the three subsystems' weightage is equal. 


\subsubsection{Coupling Coordination Degree Model}

Some studies refer to the coupling coefficient in physics $[8,34,39,65]$ in which the multi-system coupling degree model is generalized. The calculation model of the coupling degree of the ETE system in western China is expressed as:

$$
C=\left\{\frac{f(x) \times g(y) \times h(z)}{\left[\frac{f(x)+g(y)+h(z)}{3}\right]^{3}}\right\}^{\frac{1}{3}}
$$

In coupling $0 \leq C \leq 1, C$ is closer to 1 the greater the degree of coupling of the various subsystems. However, the degree of coupling can only indicate the strength of the interaction between the various subsystems and cannot reflect the level of coordinated development. Therefore, it is necessary to introduce the equation for the degree of coupling to better analyze the degree of coordination between the ETE systems which is as follows:

$$
D=\sqrt{C \times T}
$$

where, $D$ represents the CCD of the three ETE subsystems.

Referring to the research method of Chinese scholar Chongbin [66], in this study, the uniform distribution function was applied to explore the type of coupling coordination, with the degree of coupling coordination graded (Table 2).

\begin{tabular}{|c|c|c|}
\hline $\begin{array}{c}\text { Score Value of } \\
\text { Coupling Coordination }(D)\end{array}$ & Coordination Level & Coupling Development Stage \\
\hline $0-0.09$ & Extreme imbalance & \multirow{3}{*}{$\begin{array}{l}\text { Low-level coupling } \\
\text { coordination stage }\end{array}$} \\
\hline $0.10-0.19$ & Severe imbalance & \\
\hline $0.20-0.29$ & Moderate disorder & \\
\hline $0.30-0.39$ & Mild disorder & \multirow[b]{2}{*}{ Antagonism stage } \\
\hline $0.40-0.49$ & $\begin{array}{l}\text { On the verge of } \\
\text { maladjustment }\end{array}$ & \\
\hline $0.50-0.59$ & Barely tuned & \multirow{3}{*}{ Run-in stage } \\
\hline $0.60-0.69$ & Primary disorder & \\
\hline $0.70-0.79$ & Intermediate disorder & \\
\hline $0.80-0.89$ & Well discussed & \multirow{2}{*}{ High-level coupling stage } \\
\hline $0.90-1.00$ & Quality disorder & \\
\hline
\end{tabular}

Table 2. Classification standard of CCD.

\subsubsection{Spatial Autocorrelation Model}

Global autocorrelation analysis is applied to analyze the spatial distribution of the value of a certain attribute of the spatial object in the entire research area, reflecting the overall trend or spatial dependence of the observation value agglomerating within the spatial area. In simple terms, it determines if the observed value is in the global space and whether clustering occurs in the range, but it is impossible to analyze which specific areas are clustered. The clustering phenomenon is obtained by local autocorrelation analysis. The commonly used analysis method is Global Moran's I. The mathematical expression of Moran's I for spatial autocorrelation is as follows:

$$
I=\frac{n}{S_{0}} \frac{\sum_{i=1}^{n} \sum_{j=1}^{n} \omega_{i, j} z_{i} z_{j}}{\sum_{i=1}^{n} z_{i}^{2}}
$$


where, I denotes the Moran index with a value range of $(-1,1) ; \mathrm{Z} i$ is the deviation of the trait of element $i$ from its average $(X i-\bar{x}) ;$ wij is the spatial weight between element $i$ and $j ; n$ is equivalent to the total number of elements; and $S_{0}$ denotes the aggregation of all spatial weights:

$$
S_{0}=\sum_{i=1}^{n} \sum_{j=1}^{n} \omega_{i, j}
$$

\subsubsection{Spatial Durbin Regression Model}

The traditional measurement model ignores the spatial location information of the observation object and cannot reflect the spatial effect of the geographic observation object. The spatial autocorrelation test however determines that the observation object has spatial agglomeration. The spatial measurement model embeds the spatial characteristics of the data into the model, and intends to explore the spatial variation characteristics of influencing factors in different geographical locations [1]. In recent years, the commonly used spatial measurement models are the spatial lag model (SLM), the spatial error model (SEM), and the spatial Durbin model (SDM). Compared with the SLM and the SEM, the SDM is more universally applicable, and is the general form of the SLM and the SEM. Equation (12) is used for the SDM:

$$
Y=\rho W Y+X \beta+\theta W X+\partial I_{n}+\varepsilon
$$

In the equation, $Y$ represents the CCD of the ETE system in western China; $X$ represents the CCD of the ETE system; $\rho$ denotes the spatial autocorrelation coefficient; $W$ represents the space weight matrix; $W Y$ and $W X$ are the spatial lag terms of the explanatory variable and the explained variable, respectively; $\alpha$ is the constant term; $1_{n}$ is the $n \times 1$ order unit identity matrix; $\beta$ and $\theta$ are the regression coefficients; and $\varepsilon$ is the error term. When $\theta=0$ and $\rho \neq 0$, the SDM may be simplified to the SLM; if $\theta+\rho \beta=0$, the SDM may be simplified to the SEM.

\section{Results and Discussion}

\subsection{Comprehensive Development of the ETE System}

The study's analysis indicates that the performance of the overall economic system of the 12 regions is better than that of the provincial ecological system, and that the ecological system performs better than the tourism industry system, but the level of development of the ETE subsystems are showing a steady improvement. In the EE subsystem, the gap between the provinces and the cities is quite large. The comprehensive benefit value of the ETE subsystems is calculated and shown in Figures 2-4. The ETE system's comprehensive benefit value is calculated according to Equation (9) and is shown in Figure 5.

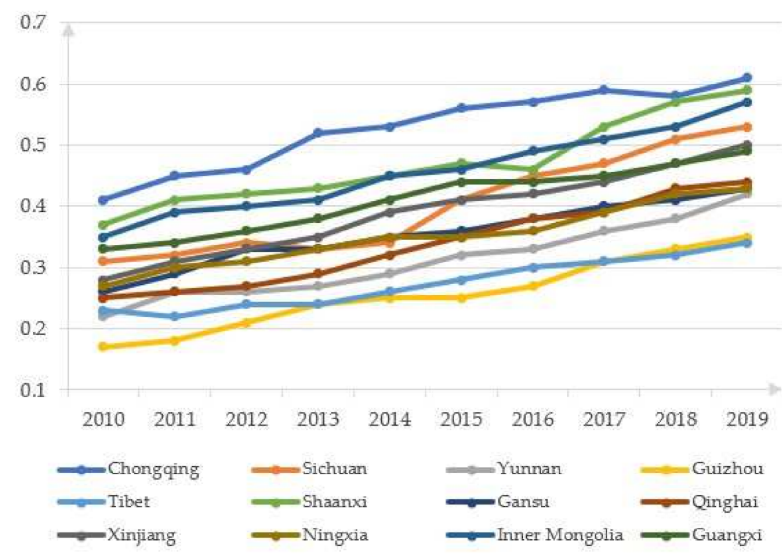

Figure 2. The regional economic subsystem development level in western China. 


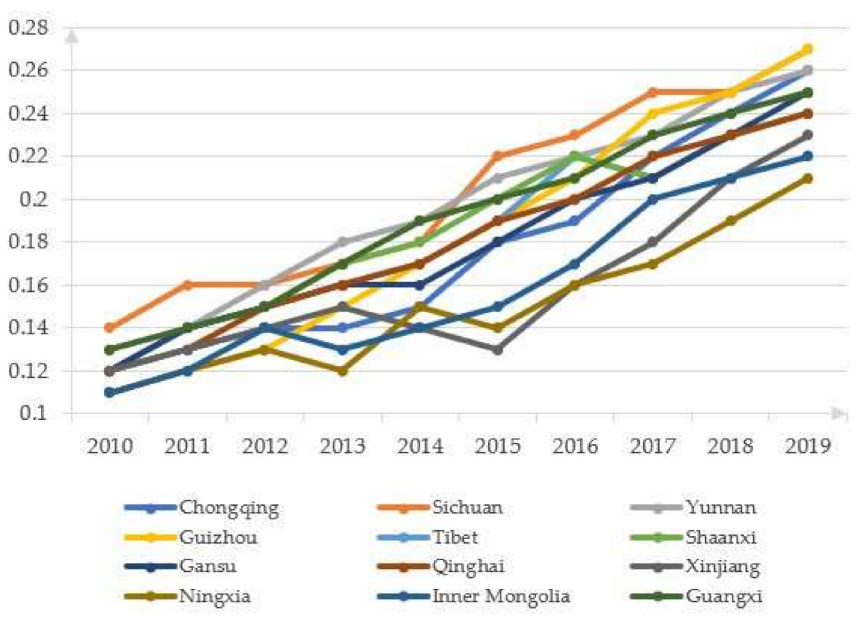

Figure 3. The tourist industry subsystem development level in western China.

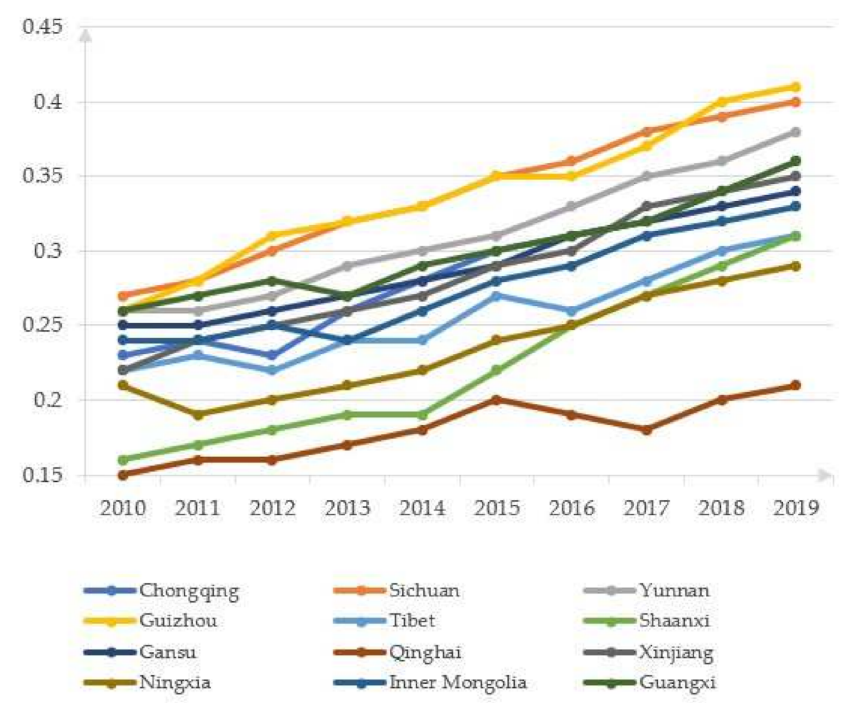

Figure 4. The EE subsystem development level in western China.

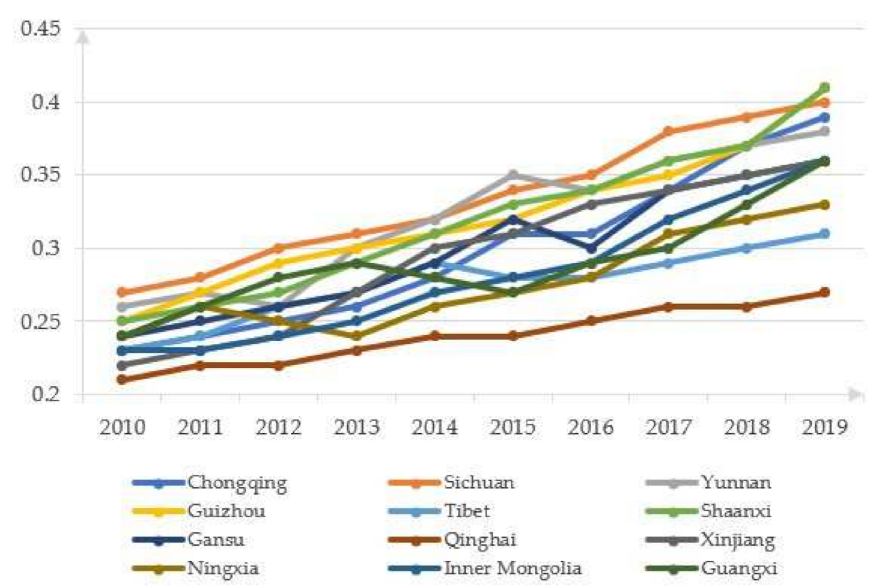

Figure 5. The ETE system development level in western China.

As presented in Figure 2, the regional economic development level of Chongqing, Shaanxi, Inner Mongolia, and Sichuan is relatively high. In contrast, the regional economic development level of Guizhou, Tibet, Yunnan, Qinghai, and other places is comparatively low. The former is taking a leading role geographically, while Guizhou, Tibet, Yunnan, 
etc., are found in south-western China. Their transportation infrastructure development is comparatively weak, with economic development lagging which, to a certain extent, is hindering the speed of their development.

As presented in Figure 3, the development gap of the tourism industry in China's western provinces and cities is relatively small. In Sichuan, Guizhou, and Yunnan, the level of growth of the tourism industry is quite high, while in Ningxia, Inner Mongolia, and Xinjiang, it is relatively low. In Sichuan province, the levels of economic development and tourism industry development are relatively high. They achieved rapid results with rich tourism resource endowment, complete transportation infrastructure, a complete public service system, and good location advantages. Although Guizhou and Yunnan have relatively poor economic development, they are rich in tourism resources and attach great importance to the self-development and protective development of these resources. The change characteristics of the EE system of the various provinces and cities in western China are different from those of the regional economy and tourism industry system (Figure 4). As demonstrated in Guizhou, Sichuan, Yunnan, and other places, higher comprehensive benefits from the EE are not significantly related to those from economic development, but are related to the tourism industry. Guizhou attaches great importance to protective development, intensive use, and low-carbon consumption in the development of tourism resources. This demonstrates no conflict between economic growth and environmental protection. The EE can be promoted by advocating ecological civilization and developing a circular economy.

As shown in Figure 5, the changing trend of the inclusive evaluation benefit value of the three major systems in western China is similar to that shown in Figure 3, while the difference in level is similar to that shown in Figure 4. To a certain extent, this shows that the tourism industry subsystem is the key to the inclusive development level of the ETE system. Sichuan relies on the advantages of the tourism economy and the EE, and its comprehensive development level is steadily rising. With its high-quality tourism and EE, Guizhou's comprehensive development level continues to rise. This shows that the three major subsystems of the ETE have an inter-related relationship, but that a benign interactive relationship has not yet formed.

\subsection{Temporal and Spatial Coupling Coordination Characteristics of the ETE System}

\subsubsection{Temporal Analysis of Coupling and CCD}

The coupling degree and CCD between the ETE systems of the provinces and cities in western China are calculated by Equations (10) and (11). The results show that the overall change pattern of the coupling degree of the ETE systems in western China from 2010-2019 is spiral in nature, with large differences in levels, with high coupling in Sichuan, Gansu, and Shanxi, and lower levels elsewhere (Figure 6). However, unlike coupling, the highest CCD of the ETE system in western China is not that of Sichuan, Shaanxi, etc., but of Guangxi, Gansu, Chongqing, etc. This is closely linked to the deployment of the Silk Road Economic Belt development strategy and regional resource endowments [35].

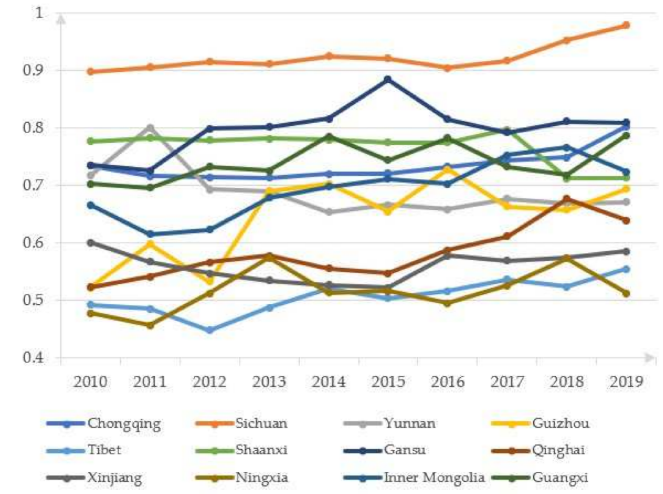

Figure 6. Temporal characteristics of the coupling degree of the ETE system in western China. 
In addition, the CCD of the ETE systems in all provinces and cities in western China is basically above 0.4 , that is, on the threshold of the coordination level. Guangxi and Gansu have the highest level of coupling coordination with the analysis showing that the value at about 0.6 in 2010 (primary disorder), and around 0.8 in 2019 (good coordination). Tibet and Guizhou grew slowly from 2010-2019, from around 0.4 in 2010 (on the verge of disorder) to around 0.5 (primary disorder) in 2019. Sichuan and Inner Mongolia have grown at a faster rate, rising by three levels in a row, from around 0.45 in 2010 (on the verge of disorder) to around 0.75 in 2019 (intermediate disorder). In particular, the ETE system in Guizhou province is relatively high in value, with the efficiency value of the tourism industry and the EE subsystems excellent, but the level of coupling coordination is relatively low with slow development. This shows that, for the three systems to promote each other, coordinated development is still needed over a lengthy time frame, requiring the provinces to focus on breaking through their own top limiting factors to achieve economic restructuring, ecological environment protection (EEP), and development of the tourism industry of the ETE coordinated synchronizations, as well as overall promotion (Figure 7).

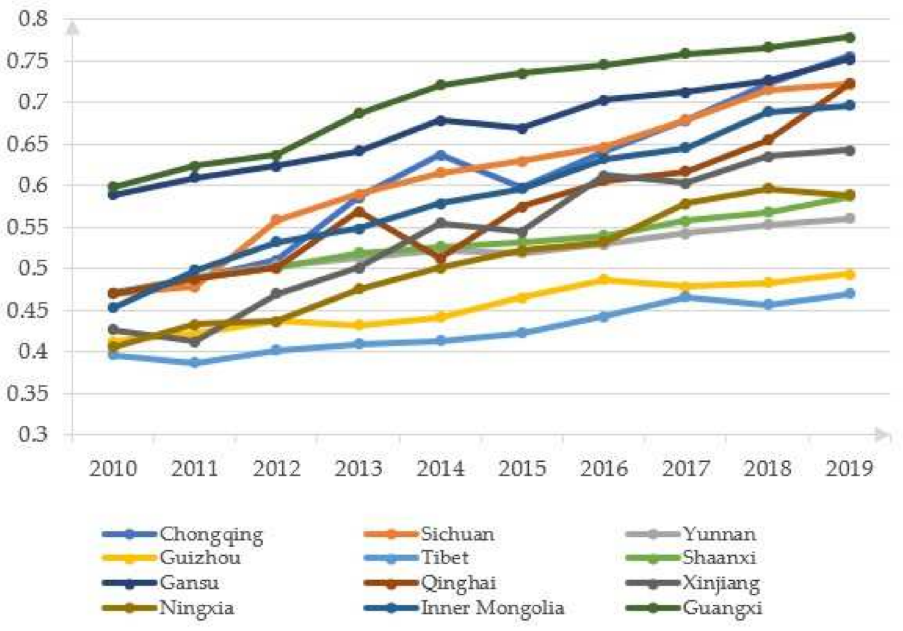

Figure 7. Timing characteristics of the CCD of the ETE system in western China.

\subsubsection{Spatial Differentiation Analysis of Coupling Coordination Degree}

Using exploratory spatial analysis, this study explores the spatial correlation of the ETE system coupling coordination and the spatial aggregation difference in western China, with spatial autocorrelation referring to the correlation of variables in different spatial locations, such as positive correlation (aggregation), negative correlation (discrete), and irrelevance (random) [67]. Moran's I index values are calculated by Geoda software for coupling coordination in 12 provinces and cities in western China from 2010-2019 (Table 3). The findings demonstrate that the Moran's I values are higher than 0 , thus indicating that a clear spatial positive correlation and spatial dependence are found at the level of ETE system coupling coordination in western China. The analysis reveals that the values in 2010 ( $z$-value is 3.125, p-value is 0.001) and in 2013 ( $z$-value is 2.138, $p$-value is 0.007) pass the significance test under the $95 \%$ confidence interval of normal distribution. This indicates a clear convergence state, that is, areas with a high CCD gather in high-level areas and low-level coupling coordination areas tend to gather in low-level areas. However, the spatial level of coupling coordination showed a downward trend over the past 10 years. The global Moran's I index value decreased from 0.112 in 2013 to 0.023 in 2019, indicating that spatial dependence has decreased significantly since 2013. This shows a decreasing spatial aggregation effect of coupling coordination in western China, with the CCD moving towards equilibrium. 
Table 3. Global Moran I Index of the ETE systems in western China.

\begin{tabular}{cccc}
\hline Years & Moran's I Index & $z$-Value & $p$-Value \\
\hline 2010 & 0.156 & 3.125 & 0.001 \\
\hline 2013 & 0.112 & 2.138 & 0.003 \\
\hline 2016 & 0.072 & 1.687 & 0.086 \\
\hline 2019 & 0.023 & 1.365 & 0.143 \\
\hline
\end{tabular}

\subsection{Analysis of Influencing Factors}

The CCD of the ETE system in western China is calculated by linear weighting of the three subsystems of regional economy, tourism industry, and the EE; however, this does not reflect how and the extent to which each subsystem acts on the ETE system. As shown in the results presented in Table 4, spatial autocorrelation exists in the CCD of the ETE system in western China, with conditions available for spatial measurement. Therefore, the current study takes the coupling coordination of every subsystem in the 12 provinces and cities in western China. The aim is to undertake an in-depth exploration of the influencing factors affecting coupling coordination and the relationship between the subsystems.

Table 4. Statistical test of SDM selection.

\begin{tabular}{cccl}
\hline Statistical Test & $\boldsymbol{t}$-Value & $\boldsymbol{p}$-Value & Decision on Null Hypothesis \\
\hline LM-lag & 49.622 & 0.000 & Rejected \\
\hline R-LM-lag & 26.383 & 0.000 & Rejected \\
\hline LM-error & 10.385 & 0.000 & Rejected \\
\hline R-LM-error & 3.456 & 0.026 & Rejected \\
\hline LR-SLM & 18.362 & 0.001 & Rejected \\
\hline LR-SEM & 17.491 & 0.001 & Rejected \\
\hline LR-time & 49.053 & 0.000 & Rejected \\
\hline LR-spatial & 114.435 & 0.000 & Rejected \\
\hline Wald-error & 18.419 & 0.002 & Rejected \\
\hline Wald-lag & 16.432 & 0.000 & Rejected \\
\hline Hausman & 59.654 & 0.000 & Rejected \\
\hline
\end{tabular}

Table 4 presents the outcomes of the SDM analysis. The Hausman test results indicate that the original hypothesis should be rejected, so a fixed effect is chosen. The likelihood ratio (LR) period fixed effect and the LR spatial fixed effect passed the $5 \%$ significance level test, so the model should be extended to the period space dual fixed effect model. However, the fixed effect of the Lagrange multiplier (LM) and R-LM test effect is the best, so they were chosen for the fixed effect model. The SLM is superior to the SEM based on the LM and R-LM test results. However, the LM and R-LM tests do not take account of the SDM's applicability. Therefore, the Wald and LR tests are required to identify whether the SDM can be simplified into an SLM or an SEM. Both the Wald and LR tests of the SLM and the SEM passed the significance test, rejecting the original hypothesis that the SDM could not be simplified. In summary, the SDM is the spatial measurement model used in this study.

Based on the selection of the above model, the spatial panel data are analyzed by effects (Table 5). The $R^{2}$ value is 0.867 and data population is found to fit well. The $\log$-likelihood $(\log \mathrm{L})$ value is 328.43 , indicating that, under certain external conditions, the selected ETE subsystem indicators, to a certain extent, can explain the coupling and coordinated development level of the ETE system, with the selected model having definite applicability. 
Table 5. SDM parameter estimation results.

\begin{tabular}{|c|c|c|c|c|c|c|c|c|}
\hline \multirow{2}{*}{ Variables } & \multicolumn{2}{|c|}{ SDM } & \multicolumn{2}{|c|}{ Direct Effect } & \multicolumn{2}{|c|}{ Indirect Effect } & \multicolumn{2}{|c|}{ Total Effect } \\
\hline & Coefficient & $p$-Value & Coefficient & $p$-Value & Coefficient & $p$-Value & Coefficient & $p$-Value \\
\hline lnecon & $1.445^{* * *}$ & 0.001 & $0.573^{* * *}$ & 0.000 & $0.398^{* * *}$ & 0.001 & $0.971^{* * *}$ & 0.045 \\
\hline $\ln t o u$ & 0.967 * & 0.016 & $0.656^{*}$ & 0.023 & 0.247 * & 0.044 & $0.903 *$ & 0.000 \\
\hline $\ln e c o e$ & $0.737^{* * *}$ & 0.000 & $0.514^{* *}$ & 0.003 & $0.318^{* * *}$ & 0.000 & $0.832 * * *$ & 0.000 \\
\hline$\rho$ & \multicolumn{8}{|c|}{$0.467^{* * *}$} \\
\hline$\sigma^{2}$ & \multicolumn{8}{|c|}{$0.000^{* * *}$} \\
\hline$R^{2}$ & \multicolumn{8}{|c|}{0.867} \\
\hline $\log L$ & \multicolumn{8}{|c|}{328.43} \\
\hline
\end{tabular}

Note: econ, tou, and ecoe, represent the regional economic subsystem, the tourism industry subsystem, and the EE subsystem, respectively; the upper corners ${ }^{* * *},{ }^{* *}$, and ${ }^{*}$ indicate statistics at $1 \%, 5 \%$, and $10 \%$ significance levels, respectively.

The regression coefficient of spatial correlation is positive and the significance test of $5 \%$ is passed, indicating the existence of a positive spatial regression effect and proving again the spatial correlation of variables. The coefficients of each subsystem are significantly positive, showing that the regional economy, tourism industry, and EE subsystems not only promote the coupling coordination of the ETE system in western China, but also promote the optimization of coupling coordination in neighboring regions. This promotes the development of the overall coupling coordination in a balanced way. In addition, the direct effect coefficient value of each subsystem is higher than the introduction effect coefficient, showing that the promotion effect of each subsystem on the coordination degree of self-coupling is greater than that of the adjacent area.

\subsection{Policy Implications}

The findings emphasize the coordination, sustainability, and tolerance levels of the development of various regions and the maintenance of the level of action to enhance the coordinated development of the ETE system in western China. Accordingly, the following suggestions are made:

(1) The demonstration drive should be taken as a carrier to build an eco-tourism demonstration zone with international influence. The southwest region is rich in tourism resources, and all provinces and regions in western China have high-quality tourism resources that could compete across the country and even worldwide. An effective measure is necessary to identify several scenic spots with good market potential and demonstration and promotion effects. The construction of a national eco-tourism demonstration zone should be accelerated following the establishment of technical standards, creating an ecotourism resource cluster with international influence, and becoming a demonstration model for the coordinated development of the global tourism economy and the EE. Guangxi, Gansu, Chongqing, etc., have a relatively high level of coupling coordination of ETE systems and should become models and benchmarks in western China. Through the "diffusion effect" and "intermediary effect," the resource elements would be promoted to spill over and radiate out to other regions in stages and steps. The promotion of industrial tax reduction and exemption should be accelerated, while also improving the talent introduction system and enhancing the advantages and potential of latecomers to this system.

(2) The "same frequency resonance" of the ETE should be vigorously promoted in the "weak areas" of western China. Firstly, various provinces and regions could make appropriate breakthroughs in the resource development spatial scope, building demonstration areas featuring original ecological and ethnic cultural tourism. The western region has abundant tourism resources and a good foundation for developing the tourism industry. Secondly, the format of the eco-tourism industry should be actively expanded, with scientific planning 
and zoning carried out in the area, forming a tourism industry cluster with a good division of labor, and focusing on the development of characteristic tourism and leisure projects.

(3) The relevant authority should take further measures and help the ETE develop steadily and harmoniously. The ecological concept of "green water and green mountains are golden mountains and silver mountains" should be implemented to break down the regional space restrictions and the administrative division barriers. This would realize the free flow of the three elements of economy-tourism-ecology (ETE), optimizing the allocation of resources, and promoting the development of inter-regional linkages. A critical policy decision on ecological environment protection should be undertaken based on the principle of "win-win" cooperation and adhering to the bottom line of environmental risk prevention and control. The relevant authorities should gain international experience to improve the ecological compensation mechanism, ensuring the fairness and testing the effectiveness of ecological compensation, and achieving cooperation and common governance, responsibility sharing, benefit sharing, tourism, and economic development to provide an excellent environment. Full attention needs to be directed to the characteristics of tourism multi-integration, combined with regional economic and cultural factors, vigorously promoting tourism and a variety of new tourism routes and tourism products. Finally, we should focus on the present as the economy is moving towards high-quality development, and we should practice the concepts of innovation, green, coordination, etc., and devote ourselves to optimizing industrial structure adjustment. Attention needs to be paid to the coordinated development of tourism and the EE, enhancing the awareness of ecological protection, establishing, and improving the cooperation framework for tourism ecological protection in western China, and promoting sustainable regional economic growth in an intensive and efficient manner.

\section{Conclusions}

Tourism development is the driving force for stimulating the economic growth of various industries, balancing international payments, and improving environmental quality. Therefore, the ETE constitutes a complex multi-level system, with interaction and mutual influence between its subsystems. This study has evaluated and analyzed the CCD of the ETE system in western China and has studied its temporal and spatial features and evolution, and has reached the following conclusions.

Firstly, from the perspective of the ETE subsystems and their overall comprehensive benefits, the ETE system has shown a gradual increasing trend. The benefit value of the regional economic system in the ETE subsystem has increased faster, driving the growth of the tourism industry subsystem. In contrast, the benefit value of the ecological environment subsystem has shown a slow growth in some areas in the past 10 years, indicating that although economic growth has driven the tourism industry's development, it has also added risks to the ecological environment.

The coupling degree and CCD of the 12 provinces and cities in western China have been improved to varying degrees in the past 10 years in the perspective of spatio-temporal variation characteristics. Although the overall trend is increasing, for example, in Guangxi and Gansu, the coupling degree of Qinghai, Ningxia, etc., began to decline in 2018. An obvious positive spatial correlation exists between the coupling coordination level of the ETE systems in western China, with this being spatially dependent. However, the spatial clustering effect has weakened, and the level of coupling coordination is developing in a balanced direction since 2013 .

From the context of the spatial spillover effects, the ETE subsystems can promote the improvement of the coupling coordination of a region and optimize the coupling coordination of neighboring areas and each subsystem. The promotion effect is greater in the latter case than the promotion effect on adjacent areas.

Author Contributions: Conceptualization, methodology, validation, formal analysis, writingoriginal draft preparation, F.Z.; writing-review and editing, F.Z., M.N.I.S. and Y.L. All authors have read and agreed to the published version of the manuscript. 
Funding: This research received no external funding.

Institutional Review Board Statement: Not applicable.

Informed Consent Statement: Not applicable.

Data Availability Statement: Not applicable.

Conflicts of Interest: The authors declare no conflict of interest.

\section{References}

1. Zhou, X.; Chen, W. The Impact of Informatization on the Relationship between the Tourism Industry and Regional Economic Development. Sustainability 2021, 13, 9399. [CrossRef]

2. Wang, Y.; Wang, M.; Li, K.; Zhao, J. Analysis of the relationships between tourism efficiency and transport accessibility-A case study in Hubei province, China. Sustainability 2021, 13, 8649. [CrossRef]

3. Pan, Y.; Weng, G.; Li, C.; Li, J. Coupling coordination and influencing factors among tourism carbon emission, tourism economic and tourism innovation. Int. J. Environ. Res. Public Health 2021, 18, 1601. [CrossRef]

4. Yuan, Y.; Jin, M.; Ren, J.; Hu, M.; Ren, P. The dynamic coordinated development of a regional environment-tourism-economy system: A case study from Western Hunan Province, China. Sustainability 2014, 6, 5231-5251. [CrossRef]

5. Zhao, Y.; Wang, S.; Zhou, C. Understanding the relation between urbanization and the eco-environment in China's Yangtze River Delta using an improved EKC model and coupling analysis. Sci. Total Environ. 2016, 571, 862-875. [CrossRef] [PubMed]

6. Zhang, Q.; Shen, J.; Sun, F. Spatiotemporal differentiation of coupling coordination degree between economic development and water environment and its influencing factors using GWR in China's province. Ecol. Modell. 2021, 462, 109794. [CrossRef]

7. Tang, Z. An integrated approach to evaluating the coupling coordination between tourism and the environment. Tour. Manag. 2015, 46, 11-19. [CrossRef]

8. Liu, C.; Zhang, R.; Wang, M.; Xu, J. Measurement and prediction of regional tourism sustainability: An analysis of the Yangtze River economic zone, China. Sustainability 2018, 10, 1321. [CrossRef]

9. Wan, J.; Zhang, L.; Yan, J.; Wang, X.; Wang, T. Spatial-temporal characteristics and influencing factors of coupled coordination between urbanization and eco-environment: A case study of 13 urban agglomerations in china. Sustainability 2020, 12, 8821. [CrossRef]

10. Li, S.; Du, S. An empirical study on the coupling coordination relationship between cultural tourism industry competitiveness and tourism flow. Sustainability 2021, 13, 5525. [CrossRef]

11. Wang, R.; Cheng, J.; Zhu, Y.; Lu, P. Evaluation on the coupling coordination of resources and environment carrying capacity in Chinese mining economic zones. Resour. Policy 2017, 53, 20-25. [CrossRef]

12. Liu, K.; Qiao, Y.; Shi, T.; Zhou, Q. Study on coupling coordination and spatiotemporal heterogeneity between economic development and ecological environment of cities along the Yellow River Basin. Environ. Sci. Pollut. Res. 2021, 28, 6898-6912. [CrossRef] [PubMed]

13. Gricar, S.; Baldigara, T.; Šugar, V. Sustainable Determinants That Affect Tourist Arrival Forecasting. Sustainability 2021, 13, 9659. [CrossRef]

14. Li, J.; Sun, W.; Li, M. Linlin Meng Coupling coordination degree of production, living and ecological spaces and its influencing factors in the Yellow River Basin. J. Clean. Prod. 2021, 298, 126803. [CrossRef]

15. Xue, Q.; Yang, X.; Wu, F. A three-stage hybrid model for the regional assessment, spatial pattern analysis and source apportionment of the land resources comprehensive supporting capacity in the Yangtze River Delta urban agglomeration. Sci. Total Environ. 2020, 711, 134428. [CrossRef] [PubMed]

16. Hong, W.; Jiang, R.; Yang, C.; Zhang, F.; Su, M.; Liao, Q. Establishing an ecological vulnerability assessment indicator system for spatial recognition and management of ecologically vulnerable areas in highly urbanized regions: A case study of Shenzhen, China. Ecol. Indic. 2016, 69, 540-547. [CrossRef]

17. Li, Y.; Li, Y.; Zhou, Y.; Shi, Y.; Zhu, X. Investigation of a coupling model of coordination between urbanization and the environment. J. Environ. Manage. 2012, 98, 127-133. [CrossRef]

18. Fan, Y.; Fang, C.; Zhang, Q. Coupling coordinated development between social economy and ecological environment in Chinese provincial capital cities-Assessment and policy implications. J. Clean. Prod. 2019, 229, 289-298. [CrossRef]

19. Lin, L.; Li, J. Analysis on the coupling relationship and coordinated development between the construction of ethnic minority tourist towns and the tourism industry. Sustainability 2021, 13, 2451. [CrossRef]

20. Wang, X.; Liu, D. The coupling coordination relationship between tourism competitiveness and economic growth of developing countries. Sustainability 2020, 12, 2350. [CrossRef]

21. Su, F.; Chang, J.; Shang, H. Coupling Coordination Analysis of Livelihood Efficiency and Land Use for Households in PovertyAlleviated Mountainous Areas. Land 2021, 10, 1115. [CrossRef]

22. Asmelash, A.G.; Kumar, S. Assessing progress of tourism sustainability: Developing and validating sustainability indicators. Tour. Manag. 2019, 71, 67-83. [CrossRef]

23. Zhao, Y.; Wang, S.; Ge, Y.; Liu, Q.; Liu, X. The spatial differentiation of the coupling relationship between urbanization and the eco-environment in countries globally: A comprehensive assessment. Ecol. Modell. 2017, 360, 313-327. [CrossRef] 
24. Cheng, Q.; Luo, Z.; Xiang, L. Spatiotemporal Differentiation of Coupling and Coordination Relationship of the Tea IndustryTourism-Ecological Environment System in Fujian Province, China. Sustainability 2021, 13, 10628. [CrossRef]

25. Zhang, K.; Liu, T.; Feng, R.; Zhang, Z.; Liu, K. Coupling coordination relationship and driving mechanism between urbanization and ecosystem service value in large regions: A case study of urban agglomeration in Yellow river basin, China. Int. J. Environ. Res. Public Health 2021, 18, 7836. [CrossRef] [PubMed]

26. Liu, Y.; Suk, S. Coupling and Coordinating Relationship between Tourism Economy and Ecological Environment—A Case Study of Nagasaki Prefecture, Japan. Int. J. Environ. Res. Public Health 2021, 18, 12818. [CrossRef] [PubMed]

27. Guo, H.; Yi, X.; Pan, C.; Yang, B.; Li, Y. Analysis on the temporal and spatial features of the coupling and coordination of industrialization and agricultural green development in China during 1990-2019. Int. J. Environ. Res. Public Health 2021, 18, 8320. [CrossRef] [PubMed]

28. Pueyo-Ros, J.; Garcia, X.; Ribas, A.; Fraguell, R.M. Ecological Restoration of a Coastal Wetland at a Mass Tourism Destination Will the Recreational Value Increase or Decrease? Ecol. Econ. 2018, 148, 1-14. [CrossRef]

29. Azam, M.; Alam, M.M.; Haroon Hafeez, M. Effect of tourism on environmental pollution: Further evidence from Malaysia, Singapore and Thailand. J. Clean. Prod. 2018, 190, 330-338. [CrossRef]

30. Fadafan, F.K.; Danehkar, A.; Pourebrahim, S. Developing a non-compensatory approach to identify suitable zones for intensive tourism in an environmentally sensitive landscape. Ecol. Indic. 2018, 87, 152-166. [CrossRef]

31. Ioan, S. Ecological Tourism and Public Administration in Romania. Procedia Soc. Behav. Sci. 2013, 81, 235-240. [CrossRef]

32. Olmsted, P.; Honey-Rosés, J.; Satterfield, T.; Chan, K.M.A. Leveraging support for conservation from ecotourists: Can relational values play a role? J. Sustain. Tour. 2020, 28, 497-514. [CrossRef]

33. Hashmi, R.; Alam, K. Dynamic relationship among environmental regulation, innovation, CO2 emissions, population, and economic growth in OECD countries: A panel investigation. J. Clean. Prod. 2019, 231, 1100-1109. [CrossRef]

34. Liao, K.C.; Yue, M.Y.; Sun, S.W.; Xue, H.B.; Liu, W.; Tsai, S.B.; Wang, J.T. An evaluation of coupling coordination between tourism and finance. Sustainability 2018, 10, 2320. [CrossRef]

35. Ariken, M.; Zhang, F.; Weng, C.N. Coupling coordination analysis and spatio-temporal heterogeneity between urbanization and eco-environment along the Silk Road Economic Belt in China. Ecol. Indic. 2021, 121, 107014. [CrossRef]

36. Muschter, S.; Caldicott, R.W.; von der Heidt, T.; Che, D. Third-party impacts of short-term rental accommodation: A community survey to inform government responses. J. Sustain. Tour. 2020, 0, 1-20. [CrossRef]

37. Liu, J.; Li, C.; Tao, J.; Ma, Y.; Wen, X. Spatiotemporal Coupling Factors and Mode of Tourism Industry, Urbanization and Ecological Environment: A Case Study of Shaanxi, China. Sustainability 2019, 11, 4923. [CrossRef]

38. Liu, W.; Jiao, F.; Ren, L.; Xu, X.; Wang, J.; Wang, X. Coupling coordination relationship between urbanization and atmospheric environment security in Jinan City. J. Clean. Prod. 2018, 204, 1-11. [CrossRef]

39. Chen, Q.; Bi, Y.; Li, J. Spatial Disparity and Influencing Factors of Coupling Coordination Development of Economy-EnvironmentTourism-Traffic: A Case Study in the Middle Reaches of Yangtze River Urban Agglomerations. Int. J. Environ. Res. Public Health 2021, 18, 7947. [CrossRef]

40. Liu, S.; Xie, X.; Zhang, X.; Zhou, C.; Cai, Y. Coordinated Development between Assistance to Tibet and Tourism Development: Spatial Patterns and Influencing Factors. Discret. Dyn. Nat. Soc. 2020, 2020, 1-13. [CrossRef]

41. Wall, G.; Wright, C. The Environmental Impact of Outdoor Recreation; Publication Series; Department of Geography, University of Waterloo: Waterloo, ON, Canada, 1977; ISBN 2019314703.

42. Stephen, L.; Smith, J. Recreational Geography: Theory and Method; Wu, B., Translator; translated in Chinese; Higher Education Press: Beijing, China, 1992.

43. Gössling, S. Global environmental consequences of tourism. Glob. Environ. Chang. 2002, 12, 283-302. [CrossRef]

44. Day, J.; Cai, L. Environmental and energy-related challenges to sustainable tourism in the United States and China. Int. J. Sustain. Dev. World Ecol. 2012, 19, 379-388. [CrossRef]

45. Sharif, A.; Godil, D.I.; Xu, B.; Sinha, A.; Rehman Khan, S.A.; Jermsittiparsert, K. Revisiting the role of tourism and globalization in environmental degradation in China: Fresh insights from the quantile ARDL approach. J. Clean. Prod. 2020, $272,122906$. [CrossRef]

46. Didenko, N.; Klochkov, Y.; Skripnuk, D. Ecological Criteria for Comparing Linear and Circular Economies. Resources 2018, 7, 48. [CrossRef]

47. Gupta, M.R.; Dutta, P.B. Tourism development, environmental pollution and economic growth: A theoretical analysis. J. Int. Trade Econ. Dev. 2018, 27, 125-144. [CrossRef]

48. Liu, Y.J.; Liu, J.; He, C.; Feng, Y. Evolution of the coupling relationship between regional development strength and resource environment level in China. Geogr. Res. 2013, 32, 507-517.

49. Dong, L.; Longwu, L.; Zhenbo, W.; Liangkan, C.; Faming, Z. Exploration of coupling effects in the Economy-Society-Environment system in urban areas: Case study of the Yangtze River Delta Urban Agglomeration. Ecol. Indic. 2021, 128, 107858. [CrossRef]

50. Li, W.; Yi, P.; Zhang, D.; Zhou, Y. Assessment of coordinated development between social economy and ecological environment: Case study of resource-based cities in Northeastern China. Sustain. Cities Soc. 2020, 59, 102208. [CrossRef]

51. Wang, J.; Han, Q.; Du, Y. Coordinated development of the economy, society and environment in urban China: A case study of 285 cities. Environ. Dev. Sustain. 2021, 2021, 1-19. [CrossRef] 
52. Liu, J.; Tian, Y.; Huang, K.; Yi, T. Spatial-temporal differentiation of the coupling coordinated development of regional energyeconomy-ecology system: A case study of the Yangtze River Economic Belt. Ecol. Indic. 2021, 124, 107394. [CrossRef]

53. Fei, J.; Lin, Y.; Jiang, Q.; Jiang, K.; Li, P.; Ye, G. Spatiotemporal coupling coordination measurement on islands' economyenvironment-tourism system. Ocean Coast. Manag. 2021, 212, 105793. [CrossRef]

54. Song, Q.; Zhou, N.; Liu, T.; Siehr, S.A.; Qi, Y. Investigation of a "coupling model" of coordination between low-carbon development and urbanization in China. Energy Policy 2018, 121, 346-354. [CrossRef]

55. Yang, Y.; Wang, L.; Yang, F.; Hu, N.; Liang, L. Evaluation of the coordination between eco-environment and socioeconomy under the "Ecological County Strategy" in western China: A case study of Meixian. Ecol. Indic. 2021, 125. [CrossRef]

56. Xiao, Y.; Li, Y.; Huang, H. Conflict or coordination? Assessment of coordinated development between socioeconomic and ecological environment in resource-based cities: Evidence from Sichuan province of China. Environ. Sci. Pollut. Res. 2021, 28, 66327-66339. [CrossRef] [PubMed]

57. Qi, P.; Xia, Z.; Zhang, G.; Zhang, W.; Chang, Z. Effects of climate change on agricultural water resource carrying capacity in a high-latitude basin. J. Hydrol. 2021, 597, 126328. [CrossRef]

58. Fang, C.; Liu, H.; Wang, S. The coupling curve between urbanization and the eco-environment: China's urban agglomeration as a case study. Ecol. Indic. 2021, 130, 108107. [CrossRef]

59. Bahtebay, J.; Zhang, F.; Ariken, M.; Chan, N.W.; Tan, M.L. Evaluation of the coordinated development of urbanization-resourcesenvironment from the incremental perspective of Xinjiang, China. J. Clean. Prod. 2021, 325, 129309. [CrossRef]

60. Zhang, T.; Li, L. Research on temporal and spatial variations in the degree of coupling coordination of tourism-urbanizationecological environment: A case study of Heilongjiang, China. Environ. Dev. Sustain. 2021, 23, 8474-8491. [CrossRef]

61. Chen, H.; Liu, L.; Fang, J.; Li, C.; Wang, L.; Quan, Q.; Liu, J. Spatio-temporal analysis of the coupling relationship between urbanization and eco-environment in backward regions of China. Environ. Sci. Pollut. Res. 2021, 29, 7406-7423. [CrossRef]

62. Fang, C.; Liu, H.; Li, G. International progress and evaluation on interactive coupling effects between urbanization and the eco-environment. J. Geogr. Sci. 2016, 26, 1081-1116. [CrossRef]

63. Fang, X.; Shi, X.; Phillips, T.K.; Du, P.; Gao, W. The Coupling Coordinated Development of Urban Environment Towards Sustainable Urbanization: An Empirical Study of Shandong Peninsula, China. Ecol. Indic. 2021, 129, 107864. [CrossRef]

64. Hou, C.; Chen, H.; Long, R. Coupling and coordination of China's economy, ecological environment and health from a green production perspective. Int. J. Environ. Sci. Technol. 2021, 1-20. [CrossRef]

65. Siebert, H.; Muller, S. Economics of the Environment; Springer: Berlin/Heidelberg, Germany, 2004; ISBN 3-540-22061-5.

66. Chongbin, L. Quantitative Evaluation and Classification System of the Coordinated Development of Environment and Economy: Taking the Pearl River Delta Urban Agglomeration as an Example. Trop. Geogr. 1999, 2, 171-177.

67. Tsai, P.-J. Application of Moran's Test with an Empirical Bayesian Rate to Leading Health Care Problems in Taiwan in a 7-Year Period (2002-2008). Glob. J. Health Sci. 2012, 4, 63-77. [CrossRef] 